\title{
Rural Fire Risk Assessment in GIS Environment Using Fuzzy Logic and the AHP Approaches
}

\author{
Ceren Erdin, Mehmet Çağlar* \\ Department of Business Administration, Faculty of Economics and Administrative Sciences, \\ Yildiz Technical University, 34220 İstanbul, Turkey
}

Received: 19 November 2020

Accepted: 21 April 2021

\begin{abstract}
Fires all around the world have caused irreparable environmental and economic losses due to the increase in global warming. Risk assessments are curial for taking measures to keep negative effects of natural hazards to a minimum and to ensure sustainability of the nature. In this regard, the aim of this study is to evaluate rural area fire risk in the seven geographical regions of Turkey. Since fire sensitive areas in rural regions are generally composed of forest areas, data on the size of forest areas, number of forest fires and temperatures are the main starting points of this study. Analysis was carried out using the Analytical Hierarchy Process and Fuzzy Logic approaches. In this study the Analytical Hierarchy Process and Fuzzy Logic approaches were integrated with the Geographical Information Systems. The results obtained from the AHP and Fuzzy Logic approaches were compared and evaluated. The results of the study show that the Aegean, Mediterranean and Marmara regions have the highest rural area fire risk levels. The fire risk assessments results obtained by the AHP and Fuzzy Logic approaches overlap on the basis of geographical regions. Integrating the AHP and Fuzzy Logic with GIS for rural area fire risk assessment provide valid, reliable and very important results in making the necessary planning and ensuring sustainability of the environment.
\end{abstract}

Keywords: fire risk assessment, geographical information systems, multi-criteria decision-making, analytical hierarchy process, fuzzy logic

\section{Introduction}

Climate change and global warming threaten our world in many ways. Especially, the natural environment is in great danger due to negative effects of the global warming. Since climate change and global warming increase the risk of extreme weather events [1] occurrence of weather-related natural disasters such

*e-mail: mcaglar@yildiz.edu.tr as floods, fires, drought and landfills rise as well [2]. These harmful consequences of climate change and global warming negatively affect Earth's natural capital and sustainable development capacity [3]. Natural disasters are events that are expected but their time and magnitude are not known and just can be predicted scientifically. Keeping the economic and social losses that will occur as a result of natural disasters at the lowest limit can be achieved with the measures to be taken according to the results of the risk analysis. By doing risk assessments, the necessary measures to be 
taken before, during and after a natural disaster can be determined scientifically.

Due to the increase in global warming, fires in forests and rural areas have caused irreparable natural and economic losses throughout the world, including Turkey. These fires have caused irreparable negative consequences for the sustainability of nature and wildlife. From 2010 to 2019, total of 24773 forest fires occurred and total of 73302 hectares forest were burned as a consequences of these fires [4, 5]. The formation of this negative picture shows us that fires in forests and rural areas pose great threats to our future. Since Mediterranean Europe (Turkey, Italy, Greece, Spain, Portugal, and France etc.) is projected to have hotter and direr warm seasons in the future [6], this region is considered to be very vulnerable region to forest and rural fires [7-12]. Therefore, the countries in the Mediterranean Europe need special attention for possible fires that may occur in the future.

The biggest fire sensitive stakeholder of rural areas is forests. Thus, rural fires should be handled within the framework of fire sensitive forest areas. Approximately 22 million hectares of forest area spread over Turkey's seven geographical regions [13] has a rich variety with its tree-type distribution, stand type and structural differences. The number of forest fires and the amount of burned area in Turkey between the years 1988-2019 [14] are shown in Fig. 1.

Rich forest areas located in all geographical regions of Turkey are under the risk of fire. Thus, fire prevention strategies are necessary to preserve these forests and minimize the damages by determining spatial distribution of fires $[15,16]$. Risk assessment is the basic element for planning and formulating strategies.

This study aims to assess rural fire risk in the seven geographical regions of Turkey. Within the scope of this study, important criteria for fire risk were determined and a short database of spatial data was gathered using the Geographical Information Systems (GIS). Weights of the criteria were calculated using the Analytical Hierarchy Process (AHP) and the fire risks of the regions were determined. Then, a fuzzy model was designed, and the required rules were created by experts. Fire risks of the regions are determined using the AHP method and fuzzy logic approach. Finally, fire risk results of the AHP and fuzzy logic models were compared.

\section{Literature Review and Theoretical Foundations}

Researchers have been putting significant efforts into risk assessment of natural hazards. One of the most important natural hazards is fire. In circumstances where uncertainty prevails, risk analysis can be carried out with many different methods. However, in order to make rational decisions about spatial problems, such methods and approaches are needed to be handled together with the GIS [17]. Because GIS applications provide the adequate tools to handle spatial data [18] and GIS-based evaluations improve the efficiency of fire risk management [19]. In recent years, GIS-based MultiCriteria Decision-Making (MCDM) techniques have been used often for risk assessment of natural hazards such as fire [20]. There are some studies using GISbased MCDM methods to assess the risk (vulnerability assessment, risk mapping etc.) of weather-related natural hazards such as fire (forest fires, wildfires etc.) [16-18, 21-25], flood [26-32], sea-level rise [33, 34], landslide [35-39], land subsidence [40, 41], drought [42, 43] and erosion [44-46].

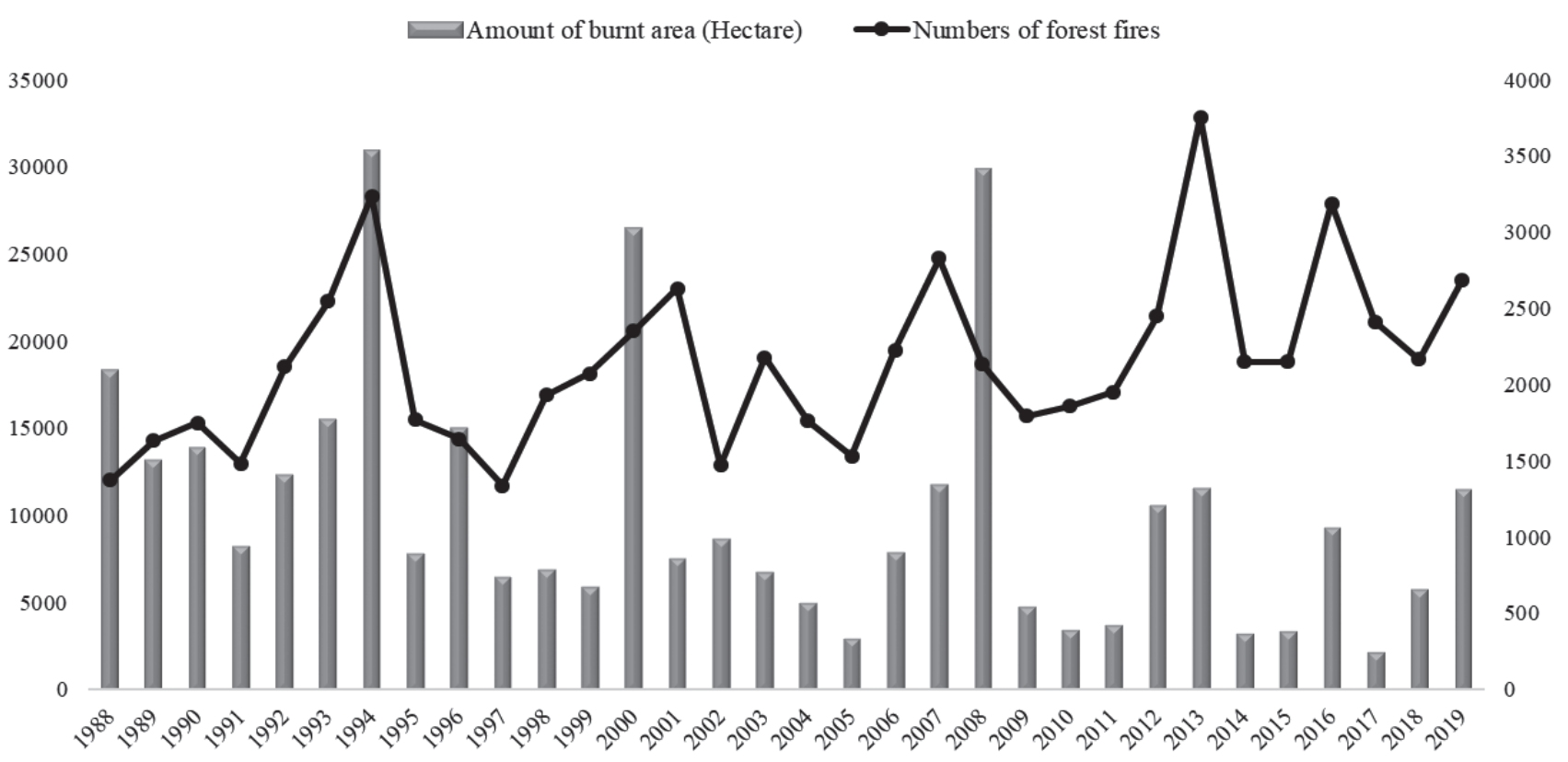

Fig. 1. The number of forest fires and the amount of burned area in Turkey (1988-2019). 
Among the MCDM methods, some studies were performed using the Analytical Hierarchy Process (AHP) [16, 23, 39, 47-49], Fuzzy AHP [18, 50], the Analytical Network Process (ANP) [24] and Fuzzy ANP [21]. Besides MCDM methods, Fuzzy Logic, which is a mathematical discipline based on fuzzy set theory, has been used in some studies [22, 24, 51]. In this study we carried out the rural fire risk assessment by GIS-based MCDM (AHP) and fuzzy logic approaches.

There are many different factors that cause fires. These factors can be summarized as topographic factors (elevation, slope, aspect) [16-19, 21-24], structural characteristics of forests (vegetation type, crown closure, stand development) [21, 49], land use/cover [10, 17, 19, 21, 23] climatic factors (temperature, humidity, precipitation, wind speed) [17, 18, 21-24], human activities/socioeconomic factors (agricultural activities, settlements, road network) [16-18, 21, 23]. Many researchers proposed different factors as causes of fires. Using too much variables may cause some challenges in risk assessment. In this study we propose to use less and specific variables for applicability of the methods, ease of analysis and generalizability of the results.

\section{Material and Methods}

The main aim of this study is to assess rural area fire risk of the seven geographical regions of Turkey. Geographical region based rural area fire risk levels are tried to be determined to provide guidance in designing fire prevention and response plans. The seven geographical regions of Turkey are Marmara, Aegean, Mediterranean, Central Anatolia, Black Sea, Eastern Anatolia and Southeastern Anatolia. These regions have different features regarding the climate, topographic structure and forest structure. Thus, the number and magnitude of rural and forest fires are different in these regions. For rural area fire risk assessment three main criteria/variable were determined: "Maximum Temperature", "Number of Fires" and "Fire Sensitive Area". Region based spatial data for these criteria was gathered using the Geographical Information Systems (GIS). Fire risks of the regions were determined using the AHP method and Fuzzy Logic approach.

\section{Study Area}

Turkey's seven geographical regions (Marmara, Aegean, Mediterranean, Central Anatolia, Black Sea, Eastern Anatolia and Southeastern Anatolia) were selected as the study area. The spatial information of the geographical regions was gathered from the database of the General Directorate of Forestry. Turkey's geographic regions are shown in Fig. 2.
Data and Method

The evaluation of Turkey's geographical areas was carried out on the basis of satellite images and databases created with remote sensing data. ArcGIS software package of ESRI Company was used in evaluations made in GIS environment. In the GIS environment, geographical boundaries, forest areas, sizes of fire sensitive areas, settlements, road networks and, the numbers and the locations of forest fires in the geographic region between 09.08.2019-20.08.2019 were determined and listed. Necessary numerical data for the AHP and linguistic data for fuzzy logic approaches were prepared. In this study vector-based spatial datasets were used. Thus, data integration was performed by using spatial databases.

In the first step, the number of forest fires experienced in all geographical regions in the same conditions and period, that is August 2019 (between 09.08.2019-20.08.2019) was gathered from the General Directorate of Forestry database. The relevant time period is the period when fires occur the most in a year. Maximum temperatures of the geographical regions during this time period were determined. Data of forest areas as fire sensitive areas $\left(\mathrm{km}^{2}\right)$ in each geographical region was gathered from the same database. Data related to the geographical regions are shown in Table 1.

When the data is examined, the maximum air temperature in the geographical regions varies between $41.8^{\circ} \mathrm{C}$ and $48.5^{\circ} \mathrm{C}$ during the period. The number of fires ranged from 12 to 60 , and the region where the most fire occurred was the Aegean region. While the region with the most fire-sensitive area is the Black Sea region $\left(57.178\right.$ thousand $\left.\mathrm{km}^{2}\right)$, the region with the least fire-sensitive area is the Southeastern Anatolia region (6.78 thousand $\mathrm{km}^{2}$ ). The rural fire risk assessment was carried out using this data.

\section{GIS-based assessment}

Geographical Information Systems (GIS) are computer systems that are designed to store, acquire, process, match and analyze spatial data [52] and implement data entry, data analysis and data presentation stages while working with spatial data [53]. By utilizing information technology, GIS helps to store, integrate, analyze and display spatial and non-spatial data. GIS uses a location referencing system so that the data of a particular location can be analyzed in its relationship with other locations [52]. Besides analysis, GIS integrates spatial and non-spatial data to create thematic maps and graphics. Since maps and other data are stored or filed as information layers in GIS, it is possible for users to perform complex analyzes. Visualization of the data is one of the important features of GIS. Using GIS, data can be displayed on two- and three-dimensional maps. This feature makes it very easy to understand the evaluation results. 


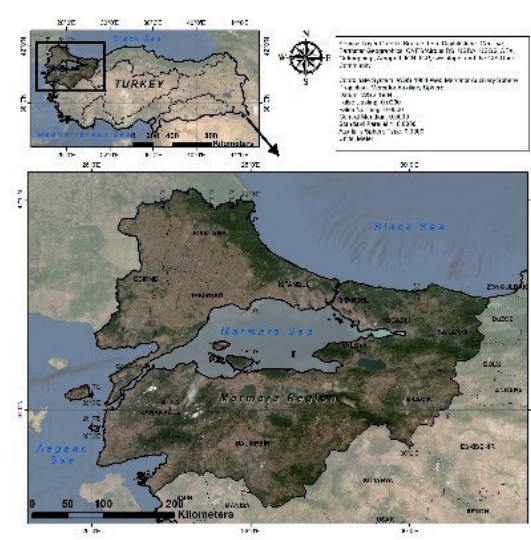

(a)

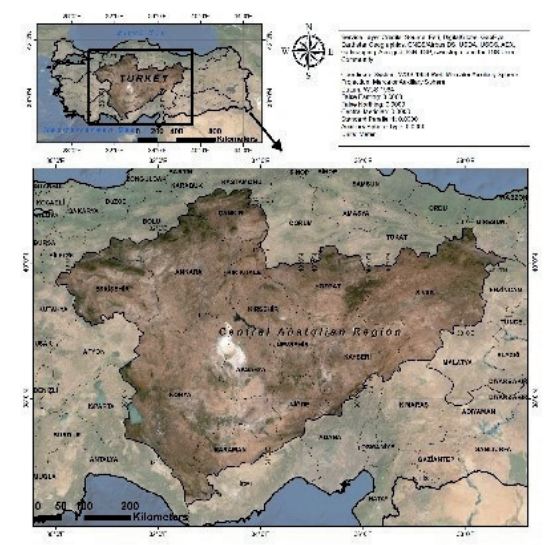

(d)
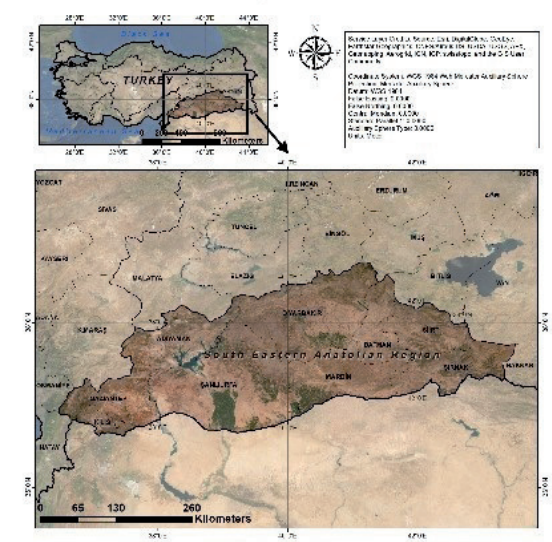

(g)

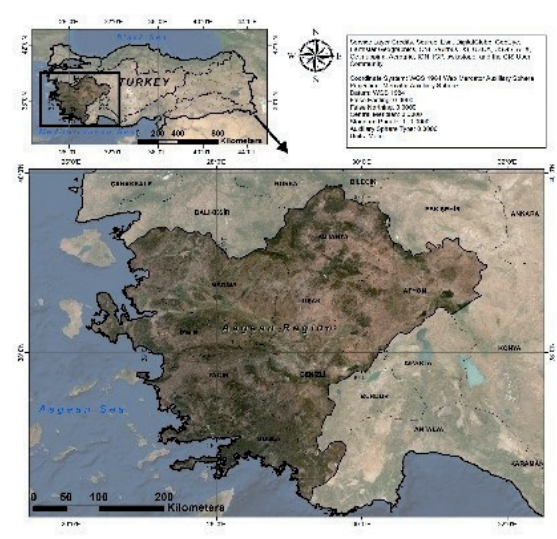

(b)
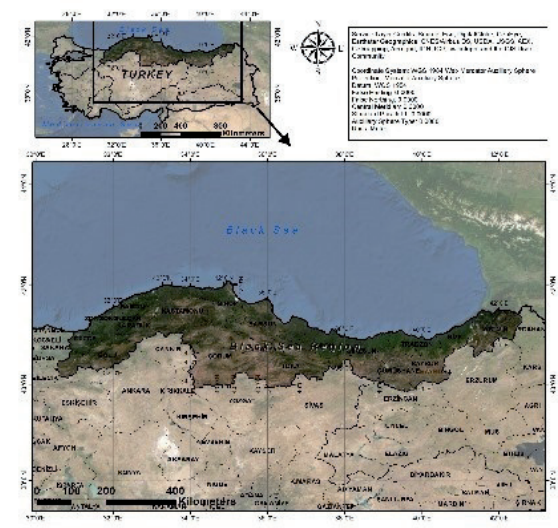

(e)

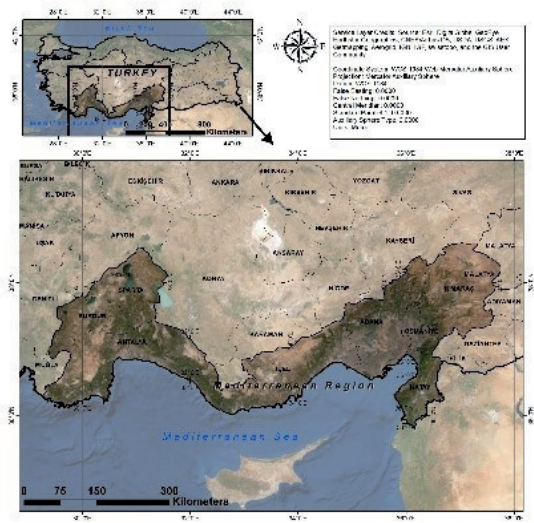

(c)
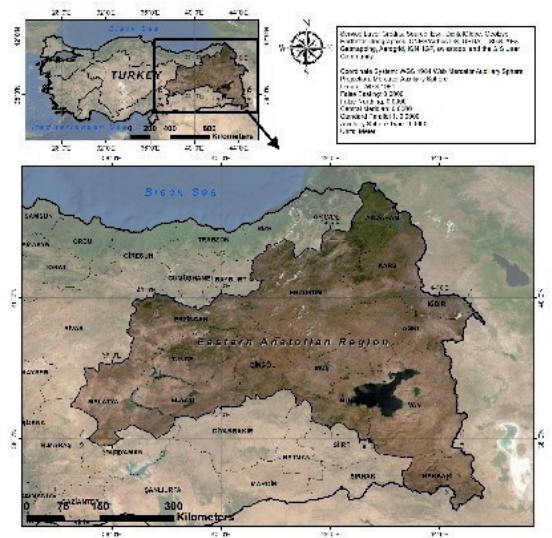

(f)

Turkey's Geographical Regions

(a) Marmara

(b) Aegean

(c) Mediterranean

(d) Central Anatolia (e) Black Sea

(f) Eastern Anatolia

(g) Southeastern Anatolia

Fig. 2. Study Area - Turkey's geographical regions.

\section{The Analytical Hierarchy Process (AHP)}

Analytical Hierarchy Process (AHP), developed by Saaty in the 1970s, is a Multi-Criteria Decision-Making (MCDP) technique used to solve complex selection and/ or prioritization problems. AHP allows both objective information and subjective judgments to be included in the decision-making process. AHP turns complex decision-making problems into simple problems by handling them in a hierarchical structure. AHP identifies decision making problems as a hierarchy with goal, criteria, sub-criteria and alternatives [54]. While the goal is at the top of the hierarchy, the criteria and sub-criteria are on lower levels, and below them, there are alternatives to achieve the goal. AHP is based on three main stages [55].

- Step 1: Creating the hierarchical stru.cture.

- Step 2: Determining the preferences.

- Step 3: Logical and numerical consistency check.

In the AHP, the importance/weights of alternatives and criteria are determined using pairwise comparisons [56]. In the pairwise comparison stage, decisions are generally made qualitatively, and these decisions are expressed numerically. The Fundamental Scale proposed by Saaty [57] is used to compare homogeneous elements (criteria, alternatives) in pairs. The Fundamental Scale 
Table 1. Data related to geographical regions.

\begin{tabular}{|c|c|c|c|}
\hline Geographical Regions & Maximum Temperature $\left({ }^{\circ} \mathrm{C}\right)$ & Number of Fires & Fire Sensitive Area $\left(\right.$ thousand $\left.\mathrm{km}^{2}\right)$ \\
\hline Marmara & 44.6 & 47 & 25.990 \\
\hline Aegean & 48.5 & 60 & 38.420 \\
\hline Mediterranean & 45.6 & 51 & 55.870 \\
\hline Central Anatolia & 41.8 & 10 & 17.402 \\
\hline Black Sea & 44.2 & 13 & 57.178 \\
\hline Eastern Anatolia & 44.4 & 17 & 24.860 \\
\hline South-eastern Anatolia & 48.2 & 12 & 6.780 \\
\hline
\end{tabular}

is a scale that contains values ranging from 1 to 9; where 1 represents equal importance between the two items, and 9 indicates the extreme importance of one item (row cluster in the matrix) in comparison to the other one [56]. Decision makers (or experts) are asked to answer pairwise comparisons based on the Fundamental Scale.

The priorities of the criteria and alternatives are derived from pairwise comparisons [56]. In the AHP, pairwise comparisons are represented as a square matrix. The main diagonal values of the matrix consist of 1 , and reciprocal values are assigned to the inverse comparisons; that is, $a_{i j}=1 / a_{i i}$, where $a_{i j}\left(a_{j i}\right)$ denotes the importance of the $i_{t h}\left(j_{t h}\right)$ element compared to the $j_{t h}\left(i_{t h}\right)$ element. The local priority vector which shows the importance level of the criteria can be derived as an estimate of the relative importance associated with the elements being compared by solving the following equation [58]:

$$
\mathrm{A} \cdot \mathrm{w}=\lambda_{\max } \cdot \mathrm{w}
$$

...where $A$ is the matrix of pairwise comparison, $w$ is the eigenvector, and $\lambda_{\max }$ is the largest eigenvalue of $A$.

The eigenvector $(w)$ can be defined as the relative priorities for the elements being compared with respect to its upper level criterion $[59,60]$. The calculation of eigenvectors $(w)$ can be algebraically represented as [61]:

$$
w_{i}=\frac{\sum_{i=1}^{I}\left(a_{i j} / \sum_{j=1}^{J} a_{i j}\right)}{J}
$$

...where, $w_{i}$ is the weighted priority for component $i, J$ is the index number of columns (components) and $I$ is the index number of rows (components).
In order to verify the validity of the model the consistency ratio (CR) of the pairwise comparison matrices are examined. The consistency ratio is calculated using the consistency index (CI) and the random index (RI). The consistency index (CI) of a pairwise comparison matrix is given as [59]:

$$
C I=\frac{\lambda_{\max }-n}{n-1}
$$

...where $\lambda_{\max }$ maximum eigenvalue and $n$ is is size of the matrix. Consistency Ratio:

$$
C R=\frac{C I}{R I}
$$

The RI value differs according to the size of a matrix. RI values for different numbers of $n$ are shown in Table 2 [59].

Where the consistency ratio is less than 0.10 , the pairwise comparison matrix is considered to have an acceptable consistency and the calculated weights are valid and can be used [59]. Decision makers must be consistent in pairwise comparisons. If the decision-makers acted inconsistently when making comparisons between criteria or between alternatives, this inconsistency is determined by calculating the consistency ratio (CR). In case of inconsistency, the decision maker has to review the pairwise comparisons.

\section{Fuzzy Logic}

Fuzzy Logic is a mathematical discipline based on fuzzy set theory. In fuzzy set logic, an element can belong to more than one set at a certain degree of membership value. In classical set logic, an element is included or excluded in a set. The fuzzy set mathematically identifies each element in the universe

Table 2. RI values according to matrix size (n).

\begin{tabular}{|c|c|c|c|c|c|c|c|c|c|c|}
\hline $\mathrm{n}$ & 1 & 2 & 3 & 4 & 5 & 6 & 7 & 8 & 9 & 10 \\
\hline $\mathrm{RI}$ & 0.00 & 0.00 & 0.58 & 0.90 & 1.12 & 1.24 & 1.32 & 1.41 & 1.45 & 1.49 \\
\hline
\end{tabular}


by assigning the element's degree of membership within the set. While the fuzzy set is characterized by membership functions, classical sets are defined by the characteristic function. In the characteristic function of classical sets, the degree can be either 0 or 1 , while the membership function can have values between 0 and 1. For this reason, membership functions are expanded version of characteristic functions [62].

We use many verbal (linguistic) terms in our daily life. The verbal terms are defined as the verbal (linguistic) variable. In a linguistic variable, the verbal terms are words that cannot fully express the boundary condition in classical set theory [63]. Linguistic variables provide approximate characterization of concepts that cannot be fully expressed. The biggest feature of fuzzy logic is the use of symbolic information rather than numbers as in classical knowledge. A second concept prevailing in fuzzy logic is experience based information methods rather than classical algorithm methods. Fuzzy logic is a logic that allows creating new designs in understanding human intelligence. Fuzzy logic is the logic of cybernetic and electronic strings [64].

Fuzzy logic allows linguistic variables that we use in daily life such as cold, hot, fast, young and small, to be used in computer systems and algorithms. Thus, it can be seen that in the solution of the problems we encounter in our daily lives, more interpretable and powerful models can be introduced. However, in systems that are based on fuzzy logic basis, experts are needed in the creation of membership functions and rule base for the problem sought. Fuzzy logic works according to linguistic values as in human logic. With this structure, Fuzzy Logic is one of the sub-branches of artificial intelligence like Expert Systems, Genetic Algorithm, and Artificial Neural Networks. As a result, the fuzzy logic approach gives machines the ability to process linguistic data of people and to work using their experience and hunch. While gaining this ability, symbolic expressions are used instead of numerical expressions. The transfer of these symbolic expressions to the machines is based on a mathematical basis. This mathematical basis is called fuzzy sets theory and fuzzy logic [64]. Fuzzy Logic systems are based on 4 basic concepts: "Fuzzy Sets", "Linguistic Variable", "Membership Functions" and "Fuzzy Rules". A typical fuzzy system is shown in Fig. 3.

The elements and processes of a typical fuzzy system can be described as follows:

Database: Where the membership functions of the fuzzy system are kept.

Rule Base: The set of fuzzy rules that the fuzzy system will use to make inferences.

Fuzzification: Converting real data coming from outside to the system into fuzzy values.

Inference System: Using fuzzy rules to obtain fuzzy outputs for fuzzy inputs.

Defuzzification: Converting the resulting fuzzy outputs to real value.

\section{Results}

\section{Fire Risk Assessment Using the AHP}

First, fire risk values of the regions were calculated by taking into consideration the data of the geographical regions (Table 2). In the AHP method, criteria are considered as Maximum Temperature (MT), Number of Fires (NoF) and Fire Sensitive Area (FSA). In the first step, normalization process is applied to each column (Table 3).

Criteria weights in the AHP method are calculated by pairwise comparisons made by the experts. In pairwise comparison stage two approaches were used. In the first approach the criteria weights were accepted as equal and in the second approach different criteria weights were calculated with the approval of the experts. Therefore, in the equal weighted AHP approach the values in the pairwise comparison matrix are assigned as 1 and in the different weighted AHP approach a comparison matrix provided by the expert was used. We aimed to determine and assess the fire risks of the regions under different criteria weights

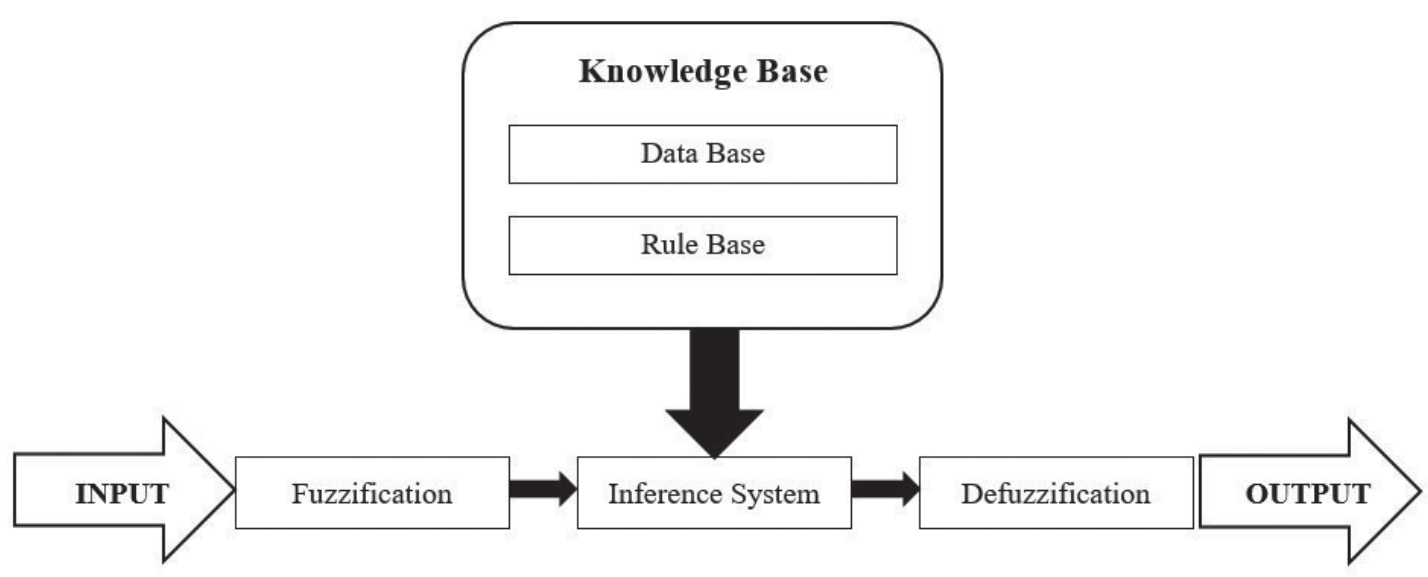

Fig. 3. A typical fuzzy system. 
Table 3. Normalized data of the Geographical Regions.

\begin{tabular}{|c|c|c|c|}
\hline Geographical Regions & Maximum Temperature & Number of Fires & Fire Sensitive Area $\left(\right.$ thousand $\left.\mathrm{km}^{2}\right)$ \\
\hline Marmara & 0.1406 & 0.2238 & 0.1147 \\
\hline Aegean & 0.1529 & 0.2857 & 0.1696 \\
\hline Mediterranean & 0.1437 & 0.2429 & 0.2467 \\
\hline Central Anatolia & 0.1317 & 0.0476 & 0.0768 \\
\hline Black Sea & 0.1393 & 0.0619 & 0.2524 \\
\hline Eastern Anatolia & 0.1399 & 0.0810 & 0.1098 \\
\hline South-eastern Anatolia & 0.1519 & 0.0571 & 0.0299 \\
\hline
\end{tabular}

Table 4. Pairwise Comparison Matrix and Criteria Weights.

\begin{tabular}{|c|c|c|c|c|c|c|}
\hline \multirow{2}{*}{ Model } & Criteria & $\begin{array}{c}\text { Maximum } \\
\text { Temperature }\end{array}$ & $\begin{array}{c}\text { Number of } \\
\text { Fires }\end{array}$ & $\begin{array}{c}\text { Fire Sensitive } \\
\text { Area }\end{array}$ & $\begin{array}{c}\text { Criteria } \\
\text { Weights }\end{array}$ & CR \\
\hline \multirow{4}{*}{$\begin{array}{c}\text { AHP-Equal } \\
\text { weighted }\end{array}$} & Maximum Temperature & 1 & 1 & 1 & 0.333 & \\
\cline { 2 - 7 } & Number of Fires & 1 & 1 & 1 & 0.333 & 0 \\
\hline \multirow{3}{*}{$\begin{array}{c}\text { AHP-Different } \\
\text { weighted }\end{array}$} & Maximum Temperature & 1 & 0.333 & 3 & 0.333 & 0.260 \\
\cline { 2 - 7 } & Number of Fires & 3 & 1 & 5 & 0.633 & 0.033 \\
\cline { 2 - 7 } & Fire Sensitive Area & 0.333 & 0.2 & 1 & 0.106 & \\
\hline
\end{tabular}

by these AHP approaches. The pairwise comparison matrices and criteria weights for the AHP models are shown in Table 4.

The consistency ratios (CR) of the AHP models are less than 0.10 . Thus the pairwise comparisons are valid and the calculated weights can be used. In the equal weighted AHP model the criteria weights are $0.333(33 \%)$. In the different weighted AHP model the most important criterion is Number of Fires (0.633), the second most important criterion is Maximum Temperature (0.260) and the least important criterion is Fire Sensitive Area (0.106). The fire risk values of the regions were calculated by multiplying the normalized data of the geographical regions (Table 3) with the criteria weights. Calculation of fire risk values:

$$
\begin{gathered}
\text { AHP - Equal weighted }=\left[\begin{array}{ccc}
0.1406 & 0.2238 & 0.1147 \\
0.1529 & 0.2857 & 0.1696 \\
0.1437 & 0.2429 & 0.2467 \\
0.1317 & 0.0476 & 0.0768 \\
0.1393 & 0.0619 & 0.2524 \\
0.1399 & 0.0810 & 0.1098 \\
0.1519 & 0.0571 & 0.0299
\end{array}\right] \\
*\left[\begin{array}{l}
0.3333 \\
0.3333 \\
0.3333
\end{array}\right]=\left[\begin{array}{c}
0.1597 \\
0.2027 \\
0.2111 \\
0.0854 \\
0.1512 \\
0.1102 \\
0.0797
\end{array}\right] \quad \begin{array}{c}
\text { Marmara (3) } \\
\text { Aegean (2) } \\
\text { Centraterranean (1) Anatolia (6) } \\
\text { Black Sea (4) } \\
\text { Southeastern Anatolia (5) Anatolia (7) }
\end{array}
\end{gathered}
$$

$$
\begin{gathered}
\text { AHP - Different weighted }=\left[\begin{array}{ccc}
0.1406 & 0.2238 & 0.1147 \\
0.1529 & 0.2857 & 0.1696 \\
0.1437 & 0.2429 & 0.2467 \\
0.1317 & 0.0476 & 0.0768 \\
0.1393 & 0.0619 & 0.2524 \\
0.1399 & 0.0810 & 0.1098 \\
0.1519 & 0.0571 & 0.0299
\end{array}\right] \\
*\left[\begin{array}{l}
0.2605 \\
0.6332 \\
0.1062
\end{array}\right]=\left[\begin{array}{l}
0.1905 \\
0.2388 \\
0.2175 \\
0.0726 \\
0.1023 \\
0.0994 \\
0.0789
\end{array}\right] \begin{array}{c}
\text { Marmara (3) } \\
\text { Aegean (1) } \\
\text { Central Anatolia (7) } \\
\text { Batack Sea (4) } \\
\text { Southeastern Anatolia (5) }
\end{array}
\end{gathered}
$$

According to the equal weighted AHP results, the region with the highest fire risk is the Mediterranean Region. Mediterranean Region is followed by Aegean Region and Marmara Region respectively. The region with the lowest risk of fire is the Southeastern Anatolia Region. According to the different weighted AHP results, the region with the highest fire risk is the Aegean Region. Aegean Region is followed by Mediterranean Region and Marmara Region respectively. The region with the lowest risk of fire is the Central Anatolia Region. The fire risk ranks of the regions differs by the AHP approaches. However, the AHP models show that the Mediterranean, Aegean and Marmara Regions have the highest rural area fire risks compared the other regions. 


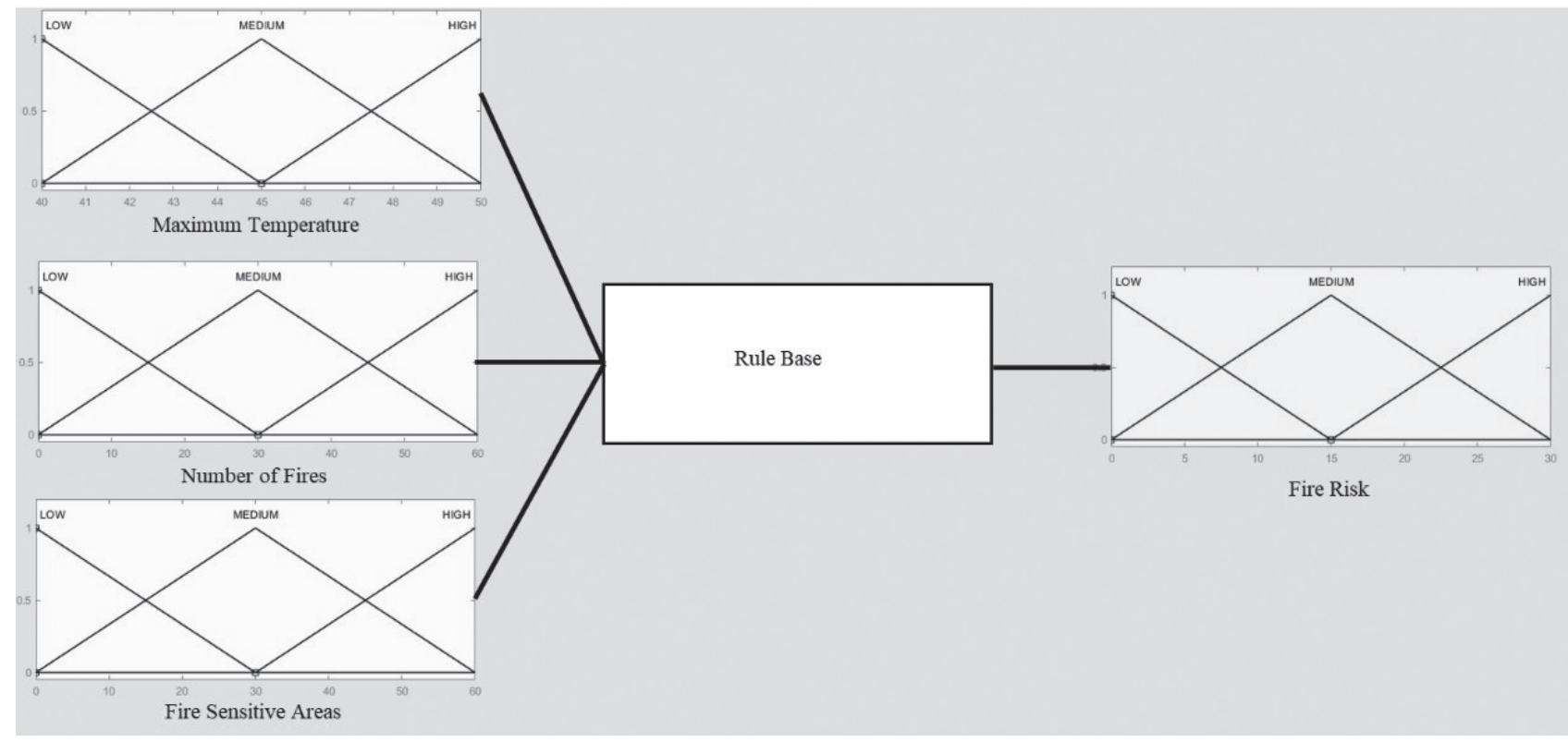

Fig. 4. The fuzzy model established to determine the fire risk.

\section{Fire Risk Assessment Uing Fuzzy Logic}

In the fuzzy logic approach, fuzzy logic modeling was performed using the data used in the AHP application. In the first step, the numerical data used in AHP method was converted into linguistic data. For example, for temperature values ranging from $40^{\circ} \mathrm{C}$ to $50^{\circ} \mathrm{C}$, linguistic variables were assigned as " $40^{\circ} \mathrm{C}-45^{\circ} \mathrm{C}=10 w ", " 45^{\circ} \mathrm{C}-50^{\circ} \mathrm{C}=$ high" and " $40^{\circ} \mathrm{C}-50^{\circ} \mathrm{C}=$ medium". Then, membership functions defined by these linguistic variables were determined.

The fuzzy model was created by MATLAB Fuzzy Logic Designer plugin. The fuzzy model consists of 3 inputs as Maximum Temperature (MT), Number of Fires (NoF) and Fire Sensitive Areas (FSA), a rule table and a fire risk output component. The fuzzy model established to determine the fire risk is shown in Fig. 4.

Expert opinions were used to create the required rule base for the calculation of the fire risk output values of the geographical regions. The model includes 3 inputs and 1 output. There are three situations for each input and output as "low", "medium" and "high". Accordingly, a total of 27 rules were created. The created rules are shown in Table 5.

3 different models were established with fuzzy logic for fire risk assessment. First, evaluation was made with the model using the raw data. Then, the data were normalized using Standard Score (Z-score) normalization and a new model was established. Finally, another model was established by normalizing the data using the Min-Max (0-1) normalization. Although the rules are the same for each model, membership functions are arranged according to the data. Membership functions of the models are given in Table 6 .
Risk assessment results using fuzzy logic in line with the established models and determined rules are shown in Table 7.

According to the results of all fuzzy logic models, the region with the highest fire risk is the Aegean Region. Besides, although the fire risk rankings are different in the model results, the first 3 regions with the highest fire risks are the same. These regions are Aegean Region, Marmara Region and Mediterranean Region.

\section{Comparison of Fire Risk Assessment Results According to the AHP and Fuzzy Logic Approaches}

While evaluating the rural fire risk of the geographical regions, results were obtained by using the AHP and Fuzzy Logic. Two different AHP models and three different Fuzzy Logic models were established. Accordingly, total of 5 different models were evaluated. Fire risk values and fire risk rankings of the geographical regions obtained as a result of all models are shown in Table 8.

Although the fire risk rankings are different, the regions with the highest fire risks according to all models are Aegean Region, Mediterranean Region and Marmara Region. However, the fire risk rankings differ depending on the model established and the method used. Spearman Rank Correlation analysis was performed to test whether there is a relationship between the results obtained from different methods and models. Correlation analysis results are given in Table 9.

According to the Spearman rank correlation analysis, the results of the AHP models are highly correlated $(r=0.929)$. There is no significant relationship 
Table 5. Rules created to determine Fire Risk

\begin{tabular}{|c|c|c|c|c|c|c|c|c|c|c|c|c|c|}
\hline 1 & If & MT & High & and & $\mathrm{NoF}$ & High & and & FSA & High & then & FR & is & High \\
\hline 2 & If & MT & High & and & $\mathrm{NoF}$ & High & and & FSA & Medium & then & FR & is & High \\
\hline 3 & If & MT & High & and & $\mathrm{NoF}$ & High & and & FSA & Low & then & FR & is & High \\
\hline 4 & If & MT & High & and & $\mathrm{NoF}$ & Medium & and & FSA & High & then & FR & is & High \\
\hline 5 & If & MT & High & and & $\mathrm{NoF}$ & Medium & and & FSA & Medium & then & FR & is & Medium \\
\hline 6 & If & MT & High & and & $\mathrm{NoF}$ & Medium & and & FSA & Low & then & FR & is & Medium \\
\hline 7 & If & MT & High & and & $\mathrm{NoF}$ & Low & and & FSA & High & then & FR & is & Medium \\
\hline 8 & If & MT & High & and & $\mathrm{NoF}$ & Low & and & FSA & Medium & then & FR & is & Low \\
\hline 9 & If & MT & High & and & $\mathrm{NoF}$ & Low & and & FSA & Low & then & FR & is & Low \\
\hline 10 & If & MT & Medium & and & $\mathrm{NoF}$ & High & and & FSA & High & then & FR & is & Medium \\
\hline 11 & If & MT & Medium & and & $\mathrm{NoF}$ & High & and & FSA & Medium & then & FR & is & Medium \\
\hline 12 & If & MT & Medium & and & $\mathrm{NoF}$ & High & and & FSA & Low & then & FR & is & Medium \\
\hline 13 & If & MT & Medium & and & $\mathrm{NoF}$ & Medium & and & FSA & High & then & FR & is & Low \\
\hline 14 & If & MT & Medium & and & $\mathrm{NoF}$ & Medium & and & FSA & Medium & then & FR & is & Medium \\
\hline 15 & If & MT & Medium & and & $\mathrm{NoF}$ & Medium & and & FSA & Low & then & FR & is & Low \\
\hline 16 & If & MT & Medium & and & $\mathrm{NoF}$ & Low & and & FSA & High & then & FR & is & Low \\
\hline 17 & If & MT & Medium & and & $\mathrm{NoF}$ & Low & and & FSA & Medium & then & FR & is & Low \\
\hline 18 & If & MT & Medium & and & $\mathrm{NoF}$ & Low & and & FSA & Low & then & FR & is & Low \\
\hline 19 & If & MT & Low & and & $\mathrm{NoF}$ & High & and & FSA & High & then & FR & is & Medium \\
\hline 20 & If & MT & Low & and & $\mathrm{NoF}$ & High & and & FSA & Medium & then & FR & is & Medium \\
\hline 21 & If & MT & Low & and & $\mathrm{NoF}$ & High & and & FSA & Low & then & FR & is & Medium \\
\hline 22 & If & MT & Low & and & NoF & Medium & and & FSA & High & then & FR & is & Medium \\
\hline 23 & If & MT & Low & and & $\mathrm{NoF}$ & Medium & and & FSA & Medium & then & FR & is & Medium \\
\hline 24 & If & MT & Low & and & $\mathrm{NoF}$ & Medium & and & FSA & Low & then & FR & is & Low \\
\hline 25 & If & MT & Low & and & NoF & Low & and & FSA & High & then & FR & is & Low \\
\hline 26 & If & MT & Low & and & $\mathrm{NoF}$ & Low & and & FSA & Medium & then & FR & is & Low \\
\hline 27 & If & MT & Low & and & NoF & Low & and & FSA & Low & then & FR & is & Low \\
\hline
\end{tabular}

*Abbreviations: MT: Maximum Temperature; NoF: Number of Fires; FSA: Fire Sensitive Area; FR: Fire Risk

between the results obtained using the equal weighted AHP (AHP-EW) method and Fuzzy-Model 1 results. On the other hand, there are significant relationships between the AHP-EW results and Fuzzy-Model 2 results at 0.714 level and between Fuzzy-Model 3 results at 0.857 level. The correlations between the different weighted AHP (AHP-DW) method and Fuzzy-Models results are significant. The biggest similarity between the AHP results and Fuzzy Logic results was revealed in the AHP-DW and Fuzzy-Model 3 where Min-Max normalization was applied to the data. Besides, all the correlation between the results of fuzzy logic models are statistically significant.

\section{Discussion}

To sum up the results, it is observed that the evaluations of rural fire risk analysis, which is performed in the GIS environment using the AHP and Fuzzy Logic approaches, overlap on the basis of geographical regions. The results of the analysis show that the regions with the highest fire risks are Aegean Region, Mediterranean Region and Marmara Region. Özgen [65] and Güney at al. [66] separately created fire risk maps for Turkey. Their fire risk results show that most part of the Mediterranean, Aegean and Marmara regions are first-degree fire sensitive areas. Our results largely overlap with their results. To validate our results, we examined the occurred fires in seven regions of 
Table 6. Fuzzy Models Membership Functions.

\begin{tabular}{|c|c|c|c|}
\hline \multirow[t]{2}{*}{ Fuzzy Model 1: } & \multicolumn{3}{|c|}{ Raw Data } \\
\hline & Low & Medium & High \\
\hline Maximum Temperature (MT) & {$\left[\begin{array}{lll}40 & 40 & 45\end{array}\right]$} & {$\left[\begin{array}{lll}40 & 45 & 50\end{array}\right]$} & {$\left[\begin{array}{lll}45 & 50 & 50\end{array}\right]$} \\
\hline Number of Fires (NoF) & {$\left[\begin{array}{lll}0 & 0 & 30\end{array}\right]$} & {$\left[\begin{array}{lll}0 & 30 & 60\end{array}\right]$} & {$\left[\begin{array}{lll}30 & 60 & 60\end{array}\right]$} \\
\hline Fire Sensitive Area (FSA) & {$\left[\begin{array}{lll}0 & 0 & 30\end{array}\right]$} & {$\left[\begin{array}{lll}0 & 30 & 60\end{array}\right]$} & {$\left[\begin{array}{lll}30 & 60 & 60\end{array}\right]$} \\
\hline Fire Risk (FR) & {$\left[\begin{array}{lll}0 & 0 & 15\end{array}\right]$} & {$\left[\begin{array}{lll}0 & 15 & 30\end{array}\right]$} & {$\left[\begin{array}{llll}15 & 30 & 30\end{array}\right]$} \\
\hline \multirow[t]{2}{*}{ Fuzzy Model 2: } & \multicolumn{3}{|c|}{ Standard Score (Z-score) normalization } \\
\hline & Low & Medium & High \\
\hline Maximum Temperature (MT) & {$\left[\begin{array}{lll}-1.96 & -1.96 & 0\end{array}\right]$} & {$\left[\begin{array}{lll}-1.96 & 0 & 1.96\end{array}\right]$} & {$\left[\begin{array}{lll}0 & 1.96 & 1.96\end{array}\right]$} \\
\hline Number of Fires (NoF) & {$\left[\begin{array}{lll}-1.96 & -1.96 & 0\end{array}\right]$} & {$\left[\begin{array}{lll}-1.96 & 0 & 1.96\end{array}\right]$} & {$\left[\begin{array}{lll}0 & 1.96 & 1.96\end{array}\right]$} \\
\hline Fire Sensitive Area (FSA) & {$\left[\begin{array}{llll}-1.96 & -1.96 & 0\end{array}\right]$} & {$\left[\begin{array}{lll}-1.96 & 0 & 1.96\end{array}\right]$} & {$\left[\begin{array}{lll}0 & 1.96 & 1.96\end{array}\right]$} \\
\hline Fire Risk (FR) & {$\left[\begin{array}{lll}-1.96 & -1.96 & 0\end{array}\right]$} & {$\left[\begin{array}{lll}-1.96 & 0 & 1.96\end{array}\right]$} & {$\left[\begin{array}{lll}0 & 1.96 & 1.96\end{array}\right]$} \\
\hline \multirow[t]{2}{*}{ Fuzzy Model 3: } & \multicolumn{3}{|c|}{ Min-Max (0-1) normalization } \\
\hline & Low & Medium & High \\
\hline Maximum Temperature (MT) & {$\left[\begin{array}{lll}0 & 0 & 0.5\end{array}\right]$} & {$\left[\begin{array}{lll}0 & 0.5 & 1\end{array}\right]$} & {$\left[\begin{array}{lll}0.5 & 1 & 1\end{array}\right]$} \\
\hline Number of Fires (NoF) & {$\left[\begin{array}{lll}0 & 0 & 0.5\end{array}\right]$} & {$\left[\begin{array}{lll}0 & 0.5 & 1\end{array}\right]$} & {$\left[\begin{array}{lll}0.5 & 1 & 1\end{array}\right]$} \\
\hline Fire Sensitive Area (FSA) & {$\left[\begin{array}{lll}0 & 0 & 0.5\end{array}\right]$} & {$\left[\begin{array}{lll}0 & 0.5 & 1\end{array}\right]$} & {$\left[\begin{array}{lll}0.5 & 1 & 1\end{array}\right]$} \\
\hline Fire Risk (FR) & {$\left[\begin{array}{lll}0 & 0 & 0.5\end{array}\right]$} & {$\left[\begin{array}{lll}0 & 0.5 & 1\end{array}\right]$} & {$\left[\begin{array}{lll}0.5 & 1 & 1\end{array}\right]$} \\
\hline
\end{tabular}

Table 7. Fire risk results obtained by the Fuzzy Logic models.

\begin{tabular}{|c|c|c|c|}
\hline \multirow{2}{*}{ Geographical Region } & \multicolumn{3}{|c|}{ Fire Risk Results } \\
\cline { 2 - 4 } & $\begin{array}{c}\text { Fuzzy Model 1 } \\
\text { (Raw Data) }\end{array}$ & $\begin{array}{c}\text { Fuzzy Model 2 } \\
\text { (Standard Score normalization) }\end{array}$ & $\begin{array}{c}\text { Fuzzy Model 3 } \\
\text { (Min-Max normalization) }\end{array}$ \\
\hline Marmara & $14.82(2)$ & $0.489(3)$ & $0.482(2)$ \\
\hline Aegean & $18.84(1)$ & $0.631(1)$ & $0.827(1)$ \\
\hline Mediterranean & $14.45(3)$ & $0.492(2)$ & $0.473(3)$ \\
\hline Central Anatolia & $11.96(6)$ & $0.436(6)$ & $0.185(7)$ \\
\hline Black Sea & $9.98(7)$ & $0.387(7)$ & $0.365(4)$ \\
\hline Eastern Anatolia & $13.60(4)$ & $0.473(4)$ & $0.364(5)$ \\
\hline Southeastern Anatolia & $12.28(5)$ & $0.448(5)$ & $0.242(6)$ \\
\hline
\end{tabular}

Turkey. Related data on the actual forest fires occurred in the regions of Turkey are gathered from official site of the Republic of Turkey General Directory of Forestry $[4,5]$. Numerical and areal distribution of forest fires by geographical region in Turkey are given in Table 10 .

In the period of 2010-2019 a total of 24773 forest fires occurred in Turkey. These fires destroyed 73302 hectares of forests. Most of the forest fires occurred in Aegean (28\%), Mediterranean (27\%) and Marmara (16\%) regions respectively. Likewise, most of the burned forest area were in Mediterranean (34\%), Aegean (26\%) and Marmara (12\%) regions respectively. In the period of $2010-2019$, approximately $71 \%$ of the forest fires and
$72 \%$ of the burned forest area occurred in these regions combined. Our fire risk assessment results and actual forest fires largely overlap. This shows that the results of this study are valid and reliable.

Public institutions make the necessary plans to prevent rural and forest fires and to reduce damages by responding to the fires as soon as possible. The first stage of the planning is to identify fire-sensitive areas and measure the fire risk levels of these areas. By this means, the most effective prevention and response planning can be made against possible fires. Spatial distribution of fires and fire risk assessment are crucial to improve fire prevention and response strategies [15] 
Table 8. Fire Risk Values and Risk Rankings of the Regions.

\begin{tabular}{|c|c|c|c|c|c|}
\hline \multirow{3}{*}{ Geographical Regions } & \multicolumn{5}{|c|}{ Rural Fire Risk } \\
\hline & \multirow{2}{*}{$\begin{array}{l}\text { AHP-Equal } \\
\text { Weighted }\end{array}$} & \multirow{2}{*}{$\begin{array}{c}\text { AHP-Different } \\
\text { Weighted }\end{array}$} & \multicolumn{3}{|c|}{ Fuzzy Logic } \\
\hline & & & $\begin{array}{l}\text { F-Model } 1 \\
\text { (Raw Data) }\end{array}$ & $\begin{array}{c}\text { F-Model } 2 \\
\text { (Standard Score normalization) }\end{array}$ & $\begin{array}{c}\text { F-Model } 3 \\
\text { (Min-Max normalization) }\end{array}$ \\
\hline Marmara & $0.1597(3)$ & $0.1905(3)$ & 14.82 & $0.489 \quad(3)$ & $0.482 \quad(2)$ \\
\hline Aegean & $0.2027(2)$ & $0.2388(1)$ & 18.84 & $0.631 \quad(1)$ & $0.827 \quad(1)$ \\
\hline Mediterranean & $0.2111(1)$ & $0.2175(2)$ & $14.45 \quad(3)$ & $0.492 \quad(2)$ & $0.473 \quad(3)$ \\
\hline Central Anatolia & $0.854(6)$ & $0.726(7)$ & $11.96(6)$ & $0.436 \quad(6)$ & $0.185 \quad(7)$ \\
\hline Black Sea & $0.1512(4)$ & $0.1023(4)$ & $9.98 \quad(7)$ & $0.387 \quad(7)$ & $0.365 \quad(4)$ \\
\hline Eastern Anatolia & $0.1102(5)$ & $0.994(5)$ & 13.60 & $0.473 \quad(4)$ & $0.364 \quad(5)$ \\
\hline Southeastern Anatolia & $0.797(7)$ & $0.789(6)$ & $12.28(5)$ & $0.448 \quad(5)$ & $0.242 \quad(6)$ \\
\hline
\end{tabular}

Table 9. Correlation Matrix.

\begin{tabular}{|c|c|c|c|c|c|}
\hline Spearman Rank Correlation & AHP-EW & AHP-DW & F-Model 1 & F-Model 2 & F-Model 3 \\
\hline AHP-EW & 1 & $0.929^{* * *}$ & 0.643 & $0.714^{*}$ & $0.857^{* *}$ \\
\hline AHP-DW & & 1 & $0.750^{*}$ & $0.786^{* *}$ & $0.964 * * *$ \\
\hline F-Model 1 & & & 1 & $0.946^{* * *}$ & $0.786^{* *}$ \\
\hline F-Model 2 & & & & 1 & $0.750^{*}$ \\
\hline F-Model 3 & & & & & 1 \\
\hline
\end{tabular}

Correlation is significant at the ${ }^{* * *} 0.01$ level, ${ }^{* *} 0.05$ level and $* 0.10$ level (2-tailed).

Table 10. Numerical and areal distribution of forest fires by geographical region in Turkey.

\begin{tabular}{|c|c|c|c|c|}
\hline \multirow{2}{*}{ Geographical Regions } & \multicolumn{2}{|c|}{ Number of forest fires } & \multicolumn{2}{c|}{ Burned forest area (hectare) } \\
\cline { 2 - 5 } & 2019 & $2010-2019$ combined & 2019 & $2010-2019$ combined \\
\hline Aegean & 604 & 7029 & 5990 & 18892 \\
\hline Mediterranean & 690 & 6799 & 1521 & 25059 \\
\hline Marmara & 517 & 3876 & 903 & 7041 \\
\hline Black Sea & 413 & 3451 & 244 & 3845 \\
\hline Central Anatolia & 138 & 2002 & 862 & 2781 \\
\hline Eastern Anatolia & 205 & 840 & 1033 & 6212 \\
\hline Southeastern Anatolia & 121 & 776 & 11332 & 73302 \\
\hline Total & 2688 & 24773 & & \\
\hline
\end{tabular}

and might be useful for planning and reducing fire risk [67]. In this point of view, this study provides guidance in fire prevention and response planning. With this study, the areas where fires pose the greatest danger in Turkey were identified as Aegean, Mediterranean and Marmara regions. Fire prevention and response planning should be concentrated in particularly these regions. The resources to be allocated to the regions can be prioritized, taking into account the fire risk levels revealed with this study. In this way, activities can be sustained effectively to prevent and respond to possible fires and economic and natural loses can be decreased to a minimum level.

\section{Conclusions}

This study aimed to assess rural fire risk in the seven geographical regions of Turkey. GIS-based AHP and fuzzy logic approaches were used for fire risk 
assessment. This study shows that integrating GIS with the AHP, which is a Multi-Criteria Decision-Making method, and Fuzzy Logic for rural fire risk assessment provide valid, reliable and very important results in making the necessary planning and taking measures for rural and forest fires. These approaches could be very useful for ensuring sustainability of forests and environment. We built different models using the AHP and fuzzy logic for fire risk assessment. Although some models give slightly different results, the regions with the highest fire risks are Aegean, Mediterranean and Marmara regions. Necessary measures must be taken to prevent possible fires and take due precautions to minimize negative consequences of this fires. Unlike some studies we only used three main causes of fire: maximum temperature, number of fires and fire sensitive area. The proposed variables and methods may be provided researchers with guidance in convenience, reliable and valid fire risk assessment and generalizability of the results.

\section{Conflict of Interest}

The authors declare no conflict of interest.

\section{References}

1. ENERGY \& CLIMATE INTELLIGENCE UNIT. Heavy Weather: Tracking the Fingerprints of Climate Change, Two Years After Paris Summit.http://www. indiaenvironmentportal.org.in/files/file/ECIU_Climate Attribution-report-Dec-2017.pdf (accessed on 09.06.2019), 2017.

2. KLING G., LO Y.C., MURINDE V., VOLZ U. Climate vulnerability and the cost of debt. SSRN: https://ssrn.com/ abstract $=3198093, \mathbf{2 0 1 8}$

3. HEIN W., WILSON C., LEE B., RAJAPAKSA D., DE MOEL H., ATHUKORALA W., MANAGI S. Climate change and natural disasters: Government mitigation activities and public property demand response. Land Use Policy, 82, 436, 2019.

4. REPUBLIC OF TURKEY GENERAL DIRECTORY OF FORESTRY. Forestry statistics: Numerical distribution to the regional directorates of forest fires, 2004-2019. Available online: https://www.ogm.gov.tr/ekutuphane/ Istatistikler/Forms/AllItems.aspx. (accessed on 5.11.2019), 2019 [In Turkish].

5. REPUBLIC OF TURKEY GENERAL DIRECTORY OF FORESTRY. Forestry statistics: The distribution of the field to the regional directorates of forest fires, 2004-2019. Available online: https:/www.ogm.gov.tr/ekutuphane/ Istatistikler/Forms/AllItems.aspx. (accessed on 05.11.2019), 2019 [In Turkish].

6. IPCC. Climate change 2014: impacts, adaptation, and vulnerability. Part A: Global and Sectoral Aspects. Contribution of Working Group II to the Fifth Assessment Report of the Intergovernmental Panel on Climate Change, Cambridge University Press: Cambridge, UK, 2014.

7. KEELEY J.E., BOND W.J., BRADSTOCK R.A., PAUSAS J.G., RUNDEL P.W. Fire in Mediterranean Ecosystems:
Ecology, Evolution and Management. Cambridge University Press: Cambridge, UK, 2011.

8. ERLAT E., TÜRKEŞ M. Observed changes and trends in numbers of summer and tropical days, and the 2010 hot summer in Turkey. International Journal of Climatology, 33 (8), 1898, 2013.

9. SATIR O., BERBEROGLU S., DONMEZ C. Mapping regional forest fire probability using artificial neural network model in a Mediterranean forest ecosystem. Geomatics, Natural Hazards and Risk, 7 (5), 1645, 2016.

10. AKAY A.E., WING M.G., ZENGIN M., KOSE O. Determination of fire-access zones along road networks in fire-sensitive forests. Journal of Forestry Research, 28 (3), 557, 2017.

11. TURCO M., VON HARDENBERG J., AGHAKOUCHAK A., LLASAT M.C., PROVENZALE A., TRIGO R.M. On the key role of droughts in the dynamics of summer fires in Mediterranean Europe. Scientific Reports, 7 (1), 1, 2017.

12. TURCO M., ROSA-CÁNOVAS J.J., BEDIA J., JEREZ S., MONTÁVEZ J.P., LLASAT M.C., PROVENZALE A. Exacerbated fires in Mediterranean Europe due to anthropogenic warming projected with non-stationary climate-fire models. Nature communications, 9 (1), 1, 2018.

13. REPUBLIC OF TURKEY GENERAL DIRECTORY OF FORESTRY. Forestry statistics: Distribution of forest land. Available online: https://www.ogm.gov.tr/ ekutuphane/Istatistikler/Forms/AllItems.aspx. (accessed on 09.06.2019), 2019 [In Turkish].

14. REPUBLIC OF TURKEY GENERAL DIRECTORY OF FORESTRY. Forestry statistics: Forest fires, 1988-2019. Available online: https://www.ogm.gov.tr/ekutuphane/ Sayfalar/Istatistikler.aspx. (accessed on 09.06.2019), 2019 [In Turkish].

15. TIAN X., ZHAO F., SHU L., WANG M. Distribution characteristics and the influence factors of forest fires in China. Forest Ecology and Management, 310, 460, 2013.

16. EUGENIO F.C., DOS SANTOS A.R., FIEDLER N.C., RIBEIRO G.A., DA SILVA A.G., DOS SANTOS Á. B., PANETO G.G., SCHETTINO V.R. Applying GIS to develop a model for forest fire risk: a case study in Espírito Santo, Brazil. Journal of Environmental Management, 173, 65, 2016.

17. ÇOBAN H., ERDIN C. Forest Fire Risk Assessment Using GIS and AHP Integration in Bucak Forest Enterprise, Turkey. Applied Ecology and Environmental Research, 18 (1), 1567, 2020.

18. ESKANDARI S. A new approach for forest fire risk modeling using fuzzy AHP and GIS in Hyrcanian forests of Iran. Arabian Journal of Geosciences, 10 (8), 190, 2017.

19. AKAY A.E., WING M.G., SIVRIKAYA F., SAKAR D.A. GIS-based decision support system for determining the shortest and safest route to forest fires: a case study in Mediterranean Region of Turkey. Environmental Monitoring and Assessment, 184 (3), 1391, 2012.

20. MOSADEGHI R., WARNKEN J., TOMLINSON R., MIRFENDERESK $H$. Uncertainty analysis in the application of multi-criteria decision-making methods in Australian strategic environmental decisions. Journal of Environmental Planning and Management, 56 (8), 1097, 2013.

21. GÜNGÖROĞLU C. Determination of forest fire risk with fuzzy analytic hierarchy process and its mapping with the application of GIS: The case of Turkey/Çakırlar. Human and Ecological Risk Assessment: An International Journal, 23 (2), 388, 2017. 
22. POURGHASEMI H.R., BEHESHTIRAD M., PRADHAN B. A comparative assessment of prediction capabilities of modified analytical hierarchy process (M-AHP) and Mamdani fuzzy logic models using Netcad-GIS for forest fire susceptibility mapping. Geomatics, Natural Hazards and Risk, 7 (2), 861, 2016.

23. NUTHAMMACHOT N., STRATOULIAS D. A GISand AHP-based approach to map fire risk: a case study of Kuan Kreng peat swamp forest, Thailand. Geocarto International, 1, 2019.

24. ABEDI GHESHLAGHI H., FEIZIZADEH B., BLASCHKE T. GIS-based forest fire risk mapping using the analytical network process and fuzzy logic. Journal of Environmental Planning and Management, 63 (3), 481, 2020.

25. ABDOLLAHI M., DEWAN A., HASSAN Q.K. Applicability of remote sensing-based vegetation water content in modeling lightning-caused Forest fire occurrences. ISPRS International Journal of GeoInformation, 8 (3), 143, 2019.

26. YANG X., DING J., HOU H. Application of a triangular fuzzy AHP approach for flood risk evaluation and response measures analysis. Natural Hazards, 68 (2), 657, 2013.

27. LI X., LI Y. Research on risk assessment system for water inrush in the karst tunnel construction based on GIS: case study on the diversion tunnel groups of the Jinping II Hydropower Station. Tunneling and Underground Space Technology, 40, 82, 2014.

28. OUMA Y.O., TATEISHI R. Urban flood vulnerability and risk mapping using integrated multi-parametric AHP and GIS: methodological overview and case study assessment. Water, 6 (6), 1515, 2014.

29. SIDDAYAO G.P., VALDEZ S.E., FERNANDEZ P.L. Analytic hierarchy process (AHP) in spatial modeling for floodplain risk assessment. International Journal of Machine Learning and Computing, 4 (5), 450, 2014.

30. PAPAIOANNOU G., VASILIADES L., LOUKAS A. Multi-criteria analysis framework for potential flood prone areas mapping. Water Resources Management, 29 (2), 399, 2015.

31. LYU H.M., SUN W.J., SHEN S.L., ARULRAJAH A. Flood risk assessment in metro systems of mega-cities using a GIS-based modeling approach. Science of the Total Environment, 626, 1012, 2018.

32. SOUISSI D., ZOUHRI L., HAMMAMI S., MSADDEK M.H., ZGHIBI A., DLALA M. GIS-based MCDM-AHP modeling for flood susceptibility mapping of arid areas, southeastern Tunisia. Geocarto International, 35 (9), 1, 2019.

33. HADIPOUR V., VAFAIE F., KERLE N. An indicatorbased approach to assess social vulnerability of coastal areas to sea-level rise and flooding: A case study of Bandar Abbas city, Iran. Ocean \& Coastal Management, 188, 105077, 2020.

34. NGUYEN T.T., WOODROFFE C.D. Assessing relative vulnerability to sea-level rise in the western part of the Mekong River Delta in Vietnam. Sustainability Science, 11 (4), 645, 2016.

35. KAYASTHA P., DHITAL M.R., DE SMEDT F. Application of the analytical hierarchy process (AHP) for landslide susceptibility mapping: A case study from the Tinau watershed, west Nepal. Computers \& Geosciences, 52, 398, 2013.

36. FEIZIZADEH B., ROODPOSHTI M.S., JANKOWSKI P., BLASCHKE T. A GIS-based extended fuzzy multi- criteria evaluation for landslide susceptibility mapping. Computers \& Geosciences, 73, 208, 2014.

37. MALLICK J., SINGH R.K., ALAWADH M.A., ISLAM S., KHAN R.A., QURESHI M.N. GIS-based landslide susceptibility evaluation using fuzzy-AHP multi-criteria decision-making techniques in the Abha Watershed, Saudi Arabia. Environmental Earth Sciences, 77 (7), 276, 2018.

38. EL JAZOULI A., BARAKAT A., KHELLOUK R. GIS-multicriteria evaluation using AHP for landslide susceptibility mapping in Oum Er Rbia high basin (Morocco). Geoenvironmental Disasters, 6 (1), 3, 2019.

39. PATTANAIK A., SINGH T.K., SAXENA M., PRUSTY B.G. Landslide Susceptibility Mapping Using AHP Along Mechuka Valley, Arunachal Pradesh, India. In Proceedings of International Conference on Remote Sensing for Disaster Management, Springer, Cham, 35, 2019.

40. TAFRESHI G.M., NAKHAEI M., LAK R. Land subsidence risk assessment using GIS fuzzy logic spatial modeling in Varamin aquifer, Iran. GeoJournal, 84, 1, 2019.

41. GHORBANZADEH O., FEIZIZADEH B., BLASCHKE $T$. An interval matrix method used to optimize the decision matrix in AHP technique for land subsidence susceptibility mapping. Environmental Earth Sciences, 77 (16), 584, 2018.

42. PALCHAUDHURI M., BISWAS S. Application of AHP with GIS in drought risk assessment for Puruliya district, India. Natural Hazards, 84 (3), 1905, 2016.

43. WIJITKOSUM S., SRIBURI T. Fuzzy AHP Integrated with GIS Analyses for Drought Risk Assessment: A Case Study from Upper Phetchaburi River Basin, Thailand. Water, 11 (5), 939, 2019.

44. SAADOUD D., HASSANI M., PEINADO F.J.M., GUETTOUCHE M.S. Application of fuzzy logic approach for wind erosion hazard mapping in Laghouat region (Algeria) using remote sensing and GIS. Aeolian Research, 32, 24, 2018.

45. ARABAMERI A., PRADHAN B., REZAEI K., CONOSCENTI C. Gully erosion susceptibility mapping using GIS-based multi-criteria decision analysis techniques. Catena, 180, 282, 2019.

46. LIN L., PUSSELLA P. Assessment of vulnerability for coastal erosion with GIS and AHP techniques case study: Southern coastline of Sri Lanka. Natural Resource Modeling, 30 (4), e12146, 2017.

47. GURRAM M.K., KINTHADA N.R. Evaluation of risk potential of industries and natural hazards in the wards of Hyderabad, India-AHP multi-criteria modeling perspective using remote sensing and GIS. In Proceedings of International Conference on Remote Sensing for Disaster Management, Springer, Cham, 317, 2019.

48. ATESOGLU A. Forest fire hazard identifying. Mapping using satellite imagery-geographic information system and analytic hierarchy process: Bartin, Turkey. Journal of Environmental Protection and Ecology, 15 (2), 715, 2014.

49. CHHETRI S.K., KAYASTHA P. Manifestation of an analytic hierarchy process (AHP) model on fire potential zonation mapping in Kathmandu Metropolitan City, Nepal. ISPRS International Journal of Geo-Information, $\mathbf{4}$ (1), 400, 2015.

50. SHARMA L.K., KANGA S., NATHAWAT M.S., SINHA S., PANDEY P.C. Fuzzy AHP for forest fire risk modeling. Disaster Prevention and Management, 21 (2), 160, 2012. 
51. SOTO M.E.C. The identification and assessment of areas at risk of forest fire using fuzzy methodology. Applied Geography, 35 (1-2), 199, 2012.

52. CHURCH R.L. Geographical information systems and location science. Computers \& Operations Research, 29 (6), 541, 2002.

53. ROLF A. Principles of Geographic Information Systems: An Introductory Texbook. The International Institute for Aerospace Survey and Earth Sciences: Enschede, The Netherlands, 2001.

54. SIPAHI S., TIMOR M. The analytic hierarchy process and analytic network process: an overview of applications. Management Decision, 48 (5), 775, 2010.

55. SAATY T.L. How to make A Decision: The Analytic Hierarchy Process. European Journal of Operational Research, 48, 9, 1990.

56. SAATY T.L. The analytic hierarchy and analytic network measurement processes: applications to decisions under risk. European Journal of Pure and Applied Mathematics, 1 (1), 122, 2007.

57. SAATY T.L. A scaling method for priorities in hierarchical structures. Journal of Mathematical Psychology, 15 (3), 234, 1977.

58. CHUNG S.H., LEE A.H., PEARN W.L. Analytic network process (ANP) approach for product mix planning in semiconductor fabricator. International Journal of Production Economics, 96 (1), 15, 2005.

59. SAATY T.L. The Analytic Hierarchy Process. McGraw Hill: New York, USA, 1980.
60. ANDERSON D.R., SWEENEY D.J., WILLIAMS T.A., CAMM J.D., COCHRAN J.J. An introduction to management science: quantitative approaches to decision making. Cengage Learning: London, UK, 2015.

61. MEADE L.M., SARKIS J.J.I.J. Analyzing organizational project alternatives for agile manufacturing processes: an analytical network approach. International Journal of Production Research, 37 (2), 241, 1999.

62. TANAKA K. An introduction to fuzzy logic for practical applications. Springer: New York, USA, 1997.

63. ZADEH L.A. The concept of a linguistic variable and its application to approximate reasoning-II. Information Sciences, 8 (4), 301, 1975.

64. ELMAS Ç. Yapay Zeka Uygulamaları. Seçkin Yayıncılık: Ankara, Turkey, 2016 [In Turkish].

65. ÖZGEN B. "Milli Hava Yangın Filosu' sözü 11 yıldır 'yerde' kaldı". İstanbul Çevre Konseyi. Available online: http://www.ick.org.tr/milli-hava-yangin-filosu-sozu-11yildir-yerde-kaldi/ (accessed on 05.11.2020), 24 August 2019 [In Turkish].

66. GÜNEY C.O., RYAN K.C., GÜNEY A., HOOD S.M. Fire Globe: Wildfire in Turkey. Wildfire Magazine, International Association of Wildland Fire. Available online: https://www.iawfonline.org/article/fire-globewildfire-in-turkey/ (accessed on 05.11.2019), 2019.

67. YANG J., HE H.S., SHIFLEY S.R., GUSTAFSON E.J. Spatial patterns of modern period human-caused fire occurrence in the Missouri Ozark Highlands. Forest Science, 53 (1), 1, 2007. 